\title{
A relação entre língua/linguagem e cultura em Benveniste: uma contribuição para as ciências humanas
}

\section{The relation between language and culture in Benveniste: a contribution to the humanities}

Daiane Neumann ${ }^{1}$, Heloisa Monteiro Rosário²

Doutoranda pelo Programa de Pós-Graduaçáo em Letras da Universidade Federal do Rio Grande do Sul (UFRGS). Bolsista

E-mail: daiane_neumann@hotmail.com

2 Doutoranda pelo Programa de Pós-

Graduação em Letras da Universidade Federal do Rio Grande do Sul (UFRGS) Professora de Francês do Instituto de

E-mail: heloisa.monteirorosario@gmail.com
RESUMO: Neste trabalho, discutimos a relação entre língua/linguagem e cultura na obra de Benveniste a fim de considerar a contribuição do linguista para as ciências humanas. Em um primeiro momento, refletimos acerca da relação entre língua/linguagem e homem, sociedade e cultura, sobretudo partindo dos debates propostos nos Problemas de linguística geral I e II. Em seguida, analisamos especificamente como se constrói a relação entre língua/linguagem e cultura em textos em que o linguista apresenta análises linguísticas. Para isso, selecionamos o texto "Religião e superstição", publicado no Vocabulário das instituições indo-europeias II, e o texto "A noção de 'ritmo' em sua expressão linguística", publicado em Problemas de linguística geral I. Ao final da pesquisa, propomos uma contribuição da obra de Benveniste para as ciências humanas.

PALAVRAS-chaVE: Benveniste; língua/linguagem; cultura.

ABSTRACT: In this paper we discuss the relation between language and culture in Benveniste's work in order to point out its contribution to the humanities. Firstly, we consider the debates concerning language and man, language and society, and language and culture, mainly the ones proposed in Problems in General Linguistics I and II. Subsequently, we examine specifically the relation between language and culture considering texts in which the linguist proposes linguistics analysis. Thus, we selected the text "Religion and superstition", published in Indo-European Language and Society II, and the text "The Notion of 'Rhythm' in its Linguistic Expression", published in Problems in General Linguistics I. Finally, we indicate a contribution of Benveniste's work to the humanities.

KEYwords: Benveniste; language; culture. 


\section{Introdução}

$\mathrm{N}^{\circ}$

o presente trabalho, discutimos a relação entre língua/linguagem e cultura em Émile Benveniste, buscando pensar, a partir dessa reflexão, uma contribuição da obra do linguista para as ciências humanas. Isso porque, atualmente, há uma preocupação dos estudiosos da obra do linguista em propor uma abertura do seu pensamento, em pensar questões que não se restringem a estudos de marcas linguísticas e que possam interessar a outras áreas das ciências humanas. No entanto, não há consenso no que se refere a essa abertura do pensamento benvenistiano. 0 que apresentamos, neste trabalho, é uma proposta de leitura da obra do linguista a fim de pensar especificamente a relação entre língua/linguagem e cultura em Benveniste.

Para tanto, partimos do princípio de que há no centro das discussões por ele propostas a preocupação com a significação. Essa questão o conduz, conforme o prefácio de Problemas de lingüística geral I, a problemáticas relacionadas à linguagem, as quais são, em seguida, inseridas por Benveniste no domínio de uma "teoria da linguagem".

Embora o linguista traga tal expressão e proponha reflexões e discussões no conjunto de sua obra que concernem a problemáticas que envolvem uma teoria da linguagem, não é possível encontrar uma definição, uma conceitualização, do que signifique tal sintagma em seus escritos. Recuperamos, por conseguinte, a noção de teoria da linguagem proposta por Henri Meschonnic em "Crise du signe", em que o teórico da linguagem afirma ter tomado emprestado a expressão de Ferdinand de Saussure, visto que foi inventada pelo mestre genebrino para se opor tanto aos estudos da linguística de seu tempo quanto à filosofia. Para Meschonnic, a teoria da linguagem é intempestiva, ela trata dos velhos problemas, da relação entre linguagem e corpo, linguagem e sujeito, linguagem e pensamento, língua e discurso, língua e literatura, língua e cultura, língua e ideias religiosas e políticas (2008a, p. 33).

No texto "A forma e o sentido na linguagem", publicado em 1966, nos Actes du XIII Congrès des Sociétés de Philosophie de langue française, em Genebra, Benveniste inicia sua reflexão destacando o fato de estar cometendo duas imprudências: tratar de uma temática que "parece convir mais a um filósofo do que a um linguista: a forma e o sentido na linguagem" (2006b, p. 220) e, por outro lado, não trazer "qualquer coisa como o ponto de vista dos linguistas; [pois] um tal ponto de vista que seja comum ao conjunto ou ao menos a uma maioria de linguistas não existe" (ibid., p. 220-221).

Tal situação coloca Benveniste em um lugar único em seu tempo, uma vez que o linguista não apenas busca construir um pensamento que não se reduz àquele do movimento estruturalista em voga no momento, mas também constata uma aversão à consideração das questões de sentido na linguagem por parte dos linguistas em geral, o que o leva ao diálogo com outras áreas das ciências humanas.

Essa postura crítica de Benveniste o conduz a uma ressignificação do seu próprio campo - a linguística - e, portanto, de seu objeto - a língua/ linguagem -, transpondo as fronteiras estabelecidas entre as áreas do conhecimento nas ciências humanas. Testemunham tal ressignificação as temáticas que perpassam as seis partes dos dois volumes dos Problemas. Em tais partes, é flagrante a preocupação de Benveniste em pensar as relações entre língua/linguagem, homem, sociedade e cultura na discussão de problemas linguísticos pertinentes a sua teorização sobre a linguagem.

Nesse sentido, em um primeiro momento, retomaremos a discussão dessas relações a partir dos textos "Da subjetividade na linguagem", "A linguagem e a experiência humana", "A forma e o sentido na linguagem" e "Estrutura da língua e estrutura da sociedade" dos 
Problemas $^{1}$. Em seguida, discutiremos como se dá especificamente a relação entre língua/linguagem e cultura a partir do texto "Religião e superstição" do segundo volume de $O$ vocabulário das instituições indo-européias ${ }^{2}$, assim como do texto "A noção de 'ritmo' na sua expressão linguística" da sexta parte - Léxico e cultura - do PLGI.

\section{Elementos para uma "teoria da linguagem": a relação língua/linguagem, homem, sociedade e cultura}

Benveniste, em "Da subjetividade na linguagem" (1958), discute a relação entre o homem e a linguagem. Sua reflexão inicia pelo questionamento de uma evidência: a linguagem é instrumento de comunicação. Concepção que se encontra em voga na época, principalmente através do pensamento de Roman Jakobson, que retoma o esquema triádico de Karl Bühler - função expressiva, função apelativa e função representativa -, acrescentando-lhe mais três funções - função fática, função metalinguística e função poética. Por outro lado, Benveniste insiste no fato de que tratar a linguagem como instrumento permite uma descrição behaviorista em termos de estímulo e resposta, na medida em que a linguagem se presta a transmitir o que se confia a ela - uma ordem, uma pergunta, um anúncio - e provoca, no interlocutor, um comportamento cada vez adequado.

Contrapondo-se a tais ideias, Benveniste afirma que a comparação da linguagem com um instrumento deve nos encher de desconfiança, como, aliás, toda noção simplista a respeito da linguagem. Para o linguista, "falar de instrumento é pôr em oposição o homem e a natureza. A picareta, a flecha,

\footnotetext{
Daqui em diante, nas citações, para nos referirmos aos Problemas de linguística geral I e aos Problemas de linguística geral II, utilizaremos PLG I e PLG II, respectivamente.

2 Embora seja uma obra traduzida, por termos consultado o texto em francês, remetemos o leitor às páginas do original, e as traduções são de nossa inteira responsabilidade.
}

a roda não estão na natureza. São fabricações. A linguagem está na natureza do homem, que não a fabricou" (2005a, p. 285), o que leva à constatação de que "não atingimos nunca o homem separado da linguagem e não o vemos nunca a inventando. Não atingimos jamais o homem reduzido a si mesmo e procurando conceber a existência do outro". Pois "é um homem falando que encontramos no mundo, um homem falando com outro homem, e a linguagem ensina a própria definição de homem" (ibid.).

Desse modo, Benveniste refuta a concepção de linguagem como instrumento de comunicação e, ao mesmo tempo, subverte a oposição entre natureza e cultura, ao afirmar que a linguagem está na natureza do homem. Conforme mostra Gérard Dessons,

Benveniste submete a noção de natureza a uma mudança contextual que implica sua reinterpretação fora do par natureza-cultura, no sentido de uma especificidade antropológica. Há uma natureza do homem que pode ser pensada em uma relação de necessidade definitória com a linguagem. A linguagem define o homem, como o homem, a linguagem (2006, p. 99) ${ }^{3}$.

Em Benveniste, portanto, a constituição do sujeito se dá na e pela linguagem ${ }^{4}$, uma vez que "só a linguagem fundamenta na realidade, na sua realidade que é a do ser, o conceito de 'ego'” (2005a, p. 286). Logo, a subjetividade de que trata o linguista está ligada à capacidade do locutor de se propor como sujeito. No entanto, o emprego do "eu" somente é possível dirigindo-se a alguém que será, na alocução, um “tu”. Tal condição de diálogo é constitutiva da categoria de pessoa, pois implica uma reciprocidade na qual

3 Tradução nossa. No original: "Benveniste fait subir à la notion de nature un changement contextuel, qui implique sa réinterprétation en dehors du couple nature-culture, dans le sens d'une spécificité anthropologique. Il y a une nature de l'homme, qui peut être pensée dans un rapport de nécessité te nécessité définitoire avec le langage. Le langage définit "homme comme l'homme le langage".

De acordo com Dessons (2006), em Benveniste, o uso da sequência na e pela não diz respeito a uma questão de estilo do autor, mas a uma figura de pensamento relacionada a um paradigma de linguagem que engloba a língua, o discurso e a enunciação. 
o "eu" se torna "tu" na alocução daquele que, a seu turno, se designa por "eu". Para Benveniste, é então em uma realidade dialética que engloba os dois termos e os define por uma relação mútua que se descobre o fundamento linguístico da subjetividade (ibid., p. 287). Com isso, Benveniste rejeita as "velhas antinomias" entre o indivíduo e a sociedade, entre o "eu" e o "outro".

Por sua vez, em "A linguagem e a experiência humana" (1965), o linguista reitera a ideia de que, desde que o pronome "eu" aparece em um enunciado evocando o pronome "tu" para se opor conjuntamente a "ele", se instaura aí, a cada vez, uma experiência humana que revela o instrumento linguístico que a funda. Ao utilizar o pronome "eu", elemento de um paradigma, o locutor o assume e o transforma em uma designação única que produz uma nova pessoa a cada vez. E é a partir dessa experiência central que se determina a possibilidade mesma do discurso.

Nessa discussão, Benveniste afirma ainda que não apenas a categoria de pessoa emerge do discurso, mas também a categoria de tempo. De acordo com seu pensamento, essa categoria apresenta as mais ricas formas linguísticas reveladoras da experiência subjetiva, na medida em que o termo tempo recobre representações bastante diferentes, mostrando que há diferentes maneiras de se propor o encadeamento das coisas. Segundo o linguista, a língua conceitualiza o tempo de um modo totalmente diferente do que faz uma reflexão relacionada ao tempo físico - um contínuo uniforme, infinito, linear, segmentável à vontade - ou relacionada ao tempo crônico - o tempo dos acontecimentos, que também diz respeito a nossa própria vida enquanto sequência de acontecimentos. Benveniste sustenta que a experiência humana do tempo se manifesta pela língua e, por isso, "o tempo linguístico manifestase irredutível igualmente ao tempo crônico e ao tempo físico" (2006a, p. 74). E é justamente o fato de se definir e de se organizar como função do discurso, de estar organicamente ligado ao exercício da fala, o que faz a singularidade do tempo linguístico.
Nesse sentido, para o autor, a expressão do tempo no sistema temporal de uma língua particular não reflete a natureza do tempo "objetivo", uma vez que a língua não está calcada na realidade. As línguas, ao contrário, nos oferecem apenas construções diversas do real a partir da elaboração de um sistema temporal complexo, sendo aqui talvez onde elas mais divergem. Além disso, o tempo do discurso não se fecha em uma subjetividade solipsista nem tampouco se reduz às divisões do tempo crônico, pois a temporalidade do "eu" que ordena o discurso é, ao mesmo tempo, aceita como sua pelo "tu". Com isso, o tempo linguístico igualmente funciona como um fator de intersubjetividade, permitindo a comunicação linguística.

Em "A forma e o sentido na linguagem" (1966), Benveniste se debruça sobre a relação entre forma e sentido, buscando reinterpretar esses dois termos, em geral concebidos como opostos, no funcionamento da língua. Pensar a relação entre forma e sentido desse modo coloca o linguista no "centro do problema mais importante, o problema da significação", pois "antes de qualquer coisa a linguagem significa, tal é seu caráter primordial, sua vocação original que transcende e explica todas as funções que ela assegura no meio humano" (2006b, p. 222). Essa constatação o faz afirmar que "bem antes de servir para comunicar, a linguagem serve para viver", uma vez que, conforme sua reflexão, diante da falta de linguagem não haveria nem a possibilidade de sociedade, nem de humanidade; o próprio da linguagem é, por conseguinte, antes de tudo, significar (ibid.).

Retomando as ideias de Saussure, a língua é, para Benveniste, em um primeiro momento, um sistema de signos. No entanto, Benveniste se incumbe da tarefa de ir além do ponto em que o mestre genebrino parou na análise da língua como sistema significante. Para tanto, o autor se pergunta sobre a frase, se pergunta sobre a função comunicativa da língua; afinal, para ele, nos comunicamos através das frases - mesmo truncadas, embrionárias, incompletas -, mas sempre por frases. Com isso, busca instaurar na língua 
uma divisão fundamental em tudo diferente daquela proposta por Saussure entre langue e parole. Há, nesse sentido, segundo o linguista, duas maneiras de ser língua na forma e no sentido. A maneira de ser língua na forma diz respeito ao "domínio semiótico"; por outro lado, a maneira de ser língua no sentido diz respeito ao "domínio semântico".

Benveniste insiste que, no domínio semiótico, não há qualquer relação do signo com as coisas denotadas nem entre a língua e o mundo. Nele, o signo tem sempre valor genérico e conceitual; as oposições semióticas são de tipo binário; e os signos se encontram em uma relação paradigmática. $\mathrm{O}$ semiótico se caracteriza, desse modo, como uma propriedade da língua. Por sua vez, conforme o linguista, há uma mudança radical de perspectiva no domínio semântico. O semântico resulta de uma atividade do locutor que coloca a língua em ação; logo, o sentido da frase implica a referência a uma situação de discurso e à atitude do locutor. A frase é, portanto, um evento diferente a cada vez, existe somente no instante em que é proferida e se apaga nesse mesmo instante. Nela, as palavras se dispõem em cadeia, e seu sentido resulta da maneira como são combinadas e empregadas. A relação entre os signos é, então, de natureza sintagmática.

Com a noção de semântico, Benveniste nos introduz no domínio da língua em emprego e em ação. A língua se torna uma mediadora entre o homem e o homem, o homem e o mundo, o espírito e as coisas, transmitindo a informação, comunicando a experiência, impondo a adesão, suscitando a resposta, implorando, constrangendo, em resumo, organizando toda a vida dos homens (ibid., p. 229). Nesse sentido, para o linguista, somente o funcionamento semântico da língua permite a integração da sociedade e a adequação ao mundo e, consequentemente, a regulação do pensamento e o desenvolvimento da consciência.

Por fim, em a "Estrutura da língua e estrutura da sociedade" (1970), Benveniste aborda a relação da língua com a sociedade. A linguagem é para o homem, conforme o linguista, um meio, sendo mesmo o único meio de atingir outro homem, de lhe transmitir e dele receber uma mensagem. Desse modo, a linguagem põe e supõe o outro; disso resulta que língua e sociedade implicam uma a outra, e que podemos e devemos estudá-las juntas, descobri-las juntas, pois juntas nasceram.

Benveniste salienta ainda que, entre os linguistas e os antropólogos, há muitas vezes o sentimento de que a sociedade e a cultura são independentes da língua. Ele igualmente observa que outros autores afirmam que a língua é o espelho da sociedade, que ela reflete a estrutura social nas suas particularidades e variações e que ela é mesmo, por excelência, um índice de mudanças que se operam na sociedade e na cultura.

A posição de Benveniste é, no entanto, totalmente outra. Ele não se propõe a estudar a relação entre língua e sociedade de um ponto de vista tipológico nem tampouco histórico ou genético. Nessa relação, Benveniste toma a língua apenas como um meio de análise da sociedade. Desse modo, a relação é de interpretante e interpretado; consequentemente, a língua é interpretante da sociedade, assim como a língua contém a sociedade. Isso significa que a sociedade "torna-se significante na e pela língua, a sociedade é o interpretado por excelência da língua” (2006c, p. 98). E é porque a língua possui dois modos de significar - o domínio semiótico e o domínio semântico - que ela se torna um instrumento próprio para descrever, conceitualizar, interpretar tanto a natureza quanto a experiência que compõem aquilo que se chama sociedade.

Assim, para Benveniste, é na prática social, no exercício da língua, na comunicação interhumana que os traços comuns do seu funcionamento deverão ser descobertos, "o homem é ainda e cada vez mais um objeto para ser descoberto, na dupla natureza que a linguagem fundamenta e instaura nele" (ibid., p. 104). 


\section{A relação entre língua/linguagem e cultura: uma questão de significação}

Benveniste, no prefácio do primeiro volume de seu $O$ vocabulário das instituições indo-europeias, afirma sua preocupação com a questão da significação na língua - e não com a questão da designação -, ao discutir a forma e o sentido na linguagem através do estudo da formação e da organização do vocabulário das instituições indo-europeias.

Segundo o autor, o termo instituição deve ser compreendido em um sentido amplo, na medida em que se refere não apenas às instituições clássicas do direito, do governo, da religião, mas também àquelas que se desenham nas técnicas, os modos de vida, as relações sociais, os processos de fala e de pensamento (1969a, p. 9). Assim como o sujeito e o tempo, a noção de instituição, portanto, é constituída na e pela linguagem, o que contribui para uma determinada concepção de sociedade e de cultura em Benveniste.

Partindo desse ponto de vista, o linguista se diferencia, de um lado, dos estudos comparatistas da época e, de outro, de estudos que se centram em aspectos históricos ou sociológicos. Com isso, Benveniste busca definir a tarefa e a contribuição específicas do linguista que não toma em suas análises nenhum pressuposto extralinguístico - daí a refutação da questão da designação -, mas tão somente o uso das formas da língua em uma dimensão diacrônica. Nessa perspectiva diacrônica, o tempo não é, então, considerado como um pano de fundo para a língua, mas sim como constituidor da significação, o que faz da dimensão temporal uma dimensão explicativa (ibid., p. 12). Finalmente, Benveniste observa ainda que tal estudo sobre a significação da linguagem poderá servir, por exemplo, a historiadores e sociólogos.

Considerando os princípios aqui expostos, discutiremos mais especificamente, neste trabalho, a relação entre língua/linguagem e cultura a partir da apresentação que Benveniste faz do termo superstição, assim como da noção de ritmo. Começamos pelo termo superstição.

No capítulo denominado "Religião e superstição", do segundo volume de seu $O$ vocabulário das instituições indo-europeias, Benveniste investiga os significados dos termos religião e superstição, buscando retraçar o processo de sua constituição semântica. Para isso, o linguista se debruça tanto sobre a relação entre ambos quanto sobre seus diferentes empregos sobretudo em grego e em latim.

O autor afirma que, do ponto de vista da forma, a palavra superstitio deveria ser o abstrato correspondente a superstes, que significa "sobrevivente" (1969b, p. 273). No entanto, levando em conta o ponto de vista do sentido, Benveniste se pergunta como relacionar esses termos, tendo em vista que superstes não significa apenas "sobrevivente", mas, em alguns empregos, também "testemunha" (ibid.). Aliás, a mesma dificuldade se apresenta para o termo superstitio em relação a superstitiosus.

A reflexão do autor inicia pelo questionamento de como superstes, adjetivo de superstare, pode significar "sobrevivente". Tal sentido está vinculado a super, que não significa somente "acima", mas também "além". Benveniste salienta, com isso, que a noção de "superioridade" não marca apenas o que está "acima", mas alguma coisa a mais, uma progressão, em relação àquilo que está abaixo. Desse modo, por exemplo, quando a morte passa em uma família, os superstites sobrevivem para além do evento; aquele que vence um perigo, uma provação, um período difícil, e que a ele sobrevive, é então o superstes (ibid., p. 276). 0 linguista observa, contudo, que este não é o único emprego de superstes: "sobreviver para além" não significa somente "ter sobrevivido a um infortúnio, à morte", mas também "ter atravessado um evento qualquer e sobrevivido para além desse evento", tendo sido disso, assim, "testemunha" (ibid.). Tal emprego, conforme Benveniste, não é isolado, e outros exemplos permitem atestar que é muito antigo. 
O linguista relaciona igualmente superstes e testis, mostrando que superstes descreve a "testemunha" seja como aquele "que sobrevive para além" (simultaneamente, testemunha e sobrevivente), seja como "aquele que se detém sobre a coisa", aquele que está aí presente. Testis, por outro lado, é aquele que assiste como um "terceiro" a uma situação que interessa a dois personagens. É o papel, em um texto sânscrito por exemplo, do deus Mitra, que por natureza é a "testemunha", pois, todas as vezes que duas pessoas estão na presença uma da outra, ele lá está como terceiro (ibid., p. 277).

Com isso, Benveniste mostra o que pode e deve significar teoricamente superstitio, qualidade de superstes. Essa será, por conseguinte, a "propriedade de estar presente" enquanto "testemunha" (ibid.). O autor salienta também que superstitio é historicamente associado a hariolatio, "predição, profecia", fato de ser "divino", e, mais frequentemente ainda, superstitiosus acompanha hariolus, "divino". A partir dessa análise, o linguista estabelece uma solução: superstitiosus é aquele que é "dotado da virtude de superstitio"; o divino é aquele que fala de uma coisa passada como se ele realmente aí estivesse estado. Nesses exemplos, portanto, o que é "adivinhado" não se aplica ao futuro, mas sim ao passado (ibid., p. 278). Como mostra o autor, superstitio é o dom de segunda vista que permite conhecer o passado como se aí se estivesse presente, superstes. É por essa razão que superstitiosus enuncia a propriedade de "dupla visão" que se atribui aos "videntes", aquela de ser "testemunha" de eventos aos quais não se assistiu.

Desse modo, Benveniste organiza tais termos da seguinte maneira: superstes é aquele que pode passar por "testemunha" pelo fato de ter assistido a algo realizado; superstitio é o "dom de presença”, faculdade de testemunhar como se aí se estivesse estado; superstitiosus é aquele que é provido de um "dom de presença" que lhe permite ter estado no passado, sentido atestado por Plauto (ibid.).
Considerando o exposto, Benveniste se interroga sobre o sentido moderno de superstição e constata que esse aparece, por último, na história semântica da palavra. O linguista observa que os romanos, tendo horror a práticas de adivinhação, as tomam por charlatanismo. Para eles, os bruxos e os adivinhas deveriam ser desprezados, ainda mais pelo fato de, em sua maioria, virem de países estrangeiros. Superstitio passa a ser associado a práticas reprovadas e toma, portanto, uma "cor desfavorável"; por isso, passa a denominar práticas de uma falsa religião consideradas como vãs e baixas (ibid., p. 279). Benveniste observa que os romanos sempre condenaram o recurso à magia, à adivinhação, a práticas julgadas pueris. É, portanto, a partir desse sentido de "crenças religiosas desprezíveis" que um adjetivo novo se formou por uma nova derivação a partir de uma palavra de base - superstitiosus, aquele que se entrega a superstitio ou que se deixa influenciar por ela (ibid.). Daí, conforme o linguista, surge uma nova ideia de superstitio, que se define em oposição a religio e que produz um novo adjetivo superstitiosus, em tudo distinto do primeiro. Nessa perspectiva, os romanos dissociaram a religio, o escrúpulo religioso, o culto autêntico, da superstitio, forma degradada, pevertida da religião (ibid.).

Assim, para Benveniste, o laço entre os dois valores sucessivos de superstitio se precisa: aquele que reflete, inicialmente, o estado das crenças populares e, depois, a atitude dos romanos tradicionais a respeito dessas crenças. Trata-se, por conseguinte, de visões de mundo que se constituem na e pela linguagem, em uma relação de imbricação mútua. Tais concepções só se tornam significantes na e pela linguagem, e a linguagem, por sua vez, se constitui nessa relação estreita com o homem, a sociedade e a cultura.

Em “A noção de 'ritmo' na sua expressão linguística” (1951), Benveniste começa se questionando sobre a noção de $\rho$ v $\theta \mu o ́$ (ritmo). Segundo o autor, os dicionários registram que $\rho v \theta \mu o ́ \varsigma$ (ritmo) é abstrato de $\rho \varepsilon \ddot{l} v$ (fluir). Não há dificuldade morfológica em relacionar $\rho v \theta \mu o ́ s$ (ritmo) e $\rho \varepsilon \omega$ (fluir); no 
entanto, em uma primeira análise, a ligação semântica que se estabelece entre essas duas palavras, por meio do "movimento regular das ondas", se revela como impossível.

Benveniste, a fim de comprovar tal tese, afirma que tanto $\rho \varepsilon \omega$ (fluir) como todos os seus derivados indicam exclusivamente a noção de "fluir", mas que o mar não "flui". Conforme o linguista, jamais se poderia dizer, então, $\rho \varepsilon i ́ v$ (fluir) a respeito do mar, e, por outro lado, jamais se emprega $\rho v \theta \mu o ́ \varsigma$

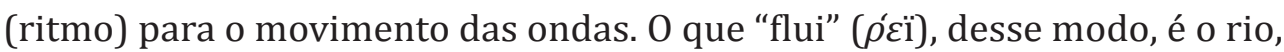
o riacho, na medida em que "uma corrente d'água não tem 'ritmo'" (2005b, p. 362). Benveniste conclui, por conseguinte, que $\rho v \theta \mu o ́ s$ (ritmo) significa fluxo, escoamento, e que não se compreende como poderia ter tomado o valor da palavra "ritmo".

O autor, buscando a comprovação de sua tese de que a palavra ritmo possui um sentido outro em relação àquele que conhecemos, apresenta, em seguida, vários usos empregados por filósofos. Benveniste faz referência ao vocabulário da antiga filosofia jônia - em especial, ao dos criadores

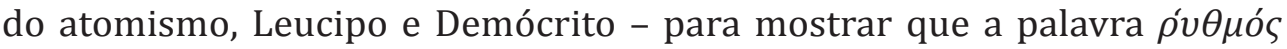
(ritmo) era um termo técnico para esses filósofos. Para o linguista, o termo $\rho v \theta \mu o ́ s$ (ritmo) tinha o sentido de "forma", o que seria confirmado por Aristóteles.

Nessa perspectiva, Benveniste conclui que não há "nenhuma variação, nenhuma ambiguidade, na significação que Demócrito atribui a $\rho v \theta \mu o ́ s$ (ritmo) e que é sempre 'forma', entendendo por aí a forma distintiva, o arranjo característico das partes num todo" (ibid., p. 364).

Em Heródoto, por sua vez, também se encontra o uso desta palavra, ao mesmo tempo que o verbo $\mu \varepsilon t \alpha \rho \rho v \theta \mu i \zeta \omega$, em um gesto particularmente interessante por tratar da "forma" das letras do alfabeto. Isso seria uma prova de uma tradição ainda mais antiga que aplicava $\rho v \theta \mu o ́ s$ (ritmo) à configuração dos signos da escrita. Benveniste acrescenta igualmente que, se procurarmos nos poetas líricos, desde o século VII, veremos $\rho v \theta \mu o ́ \varsigma$ (ritmo) no sentido de "forma" individual e distintiva do caráter humano.

$\mathrm{O}$ autor observa que, em Anacreonte, os $\rho v \theta \mu o ́ i ́$ (ritmos) são também as formas particulares do humor ou do caráter. Já entre os trágicos, $\rho v \theta \mu o ́ s$ (ritmo) e os verbos derivados guardam constantemente o mesmo sentido que nos demais textos referidos por Benveniste. Em um fragmento de Ésquilo aparece "uma forma impiedosa fez a minha forma (= condição) atual" (apud Benveniste 2005b, p. 365); em Sófocles, "por que imaginas o lugar da minha dor?" (apud Benveniste 2005b, p. 366), exatamente no sentido de "dar forma"; traduz-se, desse modo, $\rho v \theta \mu o ́ s$ (ritmo) como "imaginar", "localizar". Eurípedes fala de uma veste, da sua "forma" distintiva (apud ibid.).

Benveniste continua mostrando que esse sentido de $\rho v \theta \mu o ́ \varsigma$ (ritmo) persiste na prosa ática do século V. Xenofonte faz do $\rho v \theta \mu o ́ \varsigma$ (ritmo) a

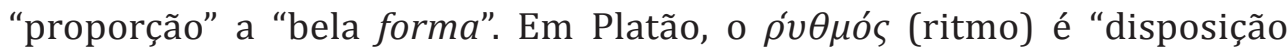
proporcionada" entre a opulência e a privação (apud ibid.).

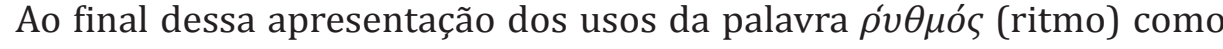
forma, disposição, o linguista aponta três conclusões importantes:

1 que $\rho v \theta \mu o ́ s$ nunca significa "ritmo" desde sua origem até o período ático; 2 o que nunca se aplica ao movimento regular das ondas; 3 o que o sentido constante é "forma distintiva, figura proporcionada, disposição", nas mais variadas condições de emprego, aliás. Igualmente os derivados ou os compostos, nominais ou verbais, de $\rho v \theta \mu o ́ s$, sempre se referem apenas à noção de "forma" (ibid.).

De acordo com Benveniste, a palavra $\rho v \theta \mu o ́ \varsigma$ (ritmo) não se confunde com outra utilizada pelos escritores gregos, $\sigma \chi \tilde{\eta} \mu \alpha$, para referir-se à forma, uma vez que esta última significa "forma fixa, realizada, posta de algum modo como objeto", enquanto que a primeira designa "a forma no instante em que é assumida por aquilo que é movediço, móvel, fluido, a forma daquilo que não tem consistência orgânica" (ibid., p. 367). 
Benveniste afirma, por conseguinte, que $\rho v \theta \mu o ́ \varsigma$ (ritmo) significa "literalmente 'maneira particular de fluir"” (ibid., p. 368) e que esse foi o termo mais “próprio para descrever 'disposições' ou 'configurações' sem fixidez nem necessidade natural, resultantes de um arranjo sempre sujeito à mudança" (ibid.).

Como o sentido de "forma" foi o único atestado até meados do século $\mathrm{V}$, o autor sustenta que o sentido moderno de "ritmo" derivaria de uma especialização secundária. Segundo Benveniste, foi Platão quem precisou a noção de "ritmo", apresentando uma acepção nova em relação ao valor

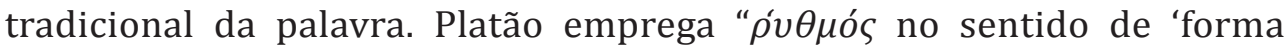
distintiva, disposição, proporção'. Inova, aplicando-o à forma do movimento que o corpo humano executa na dança, e à disposição das figuras nas quais se resolve esse movimento" (ibid., p. 369). Essa forma é, conforme o linguista, determinada por uma "medida" sujeita a uma ordem, que toma em Platão o sentido de "uma seqüência ordenada de movimentos lentos e rápidos, assim como a 'harmonia' resulta da alternância do agudo e do grave” (ibid.). É à ordem no movimento, a todo o processo do arranjo harmonioso das atitudes corporais combinado com um metro, que se chama a partir daí $\rho v \theta \mu o ́ s$.

A partir desse momento, para Benveniste, pode-se falar no ritmo de uma marcha, de um canto, da dicção, de um trabalho, de tudo o que supõe uma atividade contínua decomposta pelo metro em tempos alternados. A noção de ritmo está, então, fixada. Partindo do $\rho v \theta \mu o ́ \varsigma$, configuração espacial definida pelo arranjo e pela proporção distintivos dos elementos, o linguista afirma que se chega à definição de ritmo como "a configuração dos movimentos ordenados na duração" (ibid., p. 370).

Na parte final de sua reflexão, Benveniste salienta o fato de estar bem longe de representações simplistas que uma etimologia superficial sugeriria, na medida em que, com sua análise, mostra que não foi contemplando o jogo das vagas na praia que o heleno primitivo descobriu o "ritmo", mas que somos nós quem o metaforizamos, hoje, quando falamos de ritmo das ondas. Para que fosse possível reconhecer e denominar o princípio do movimento cadenciado, portanto, foram necessárias, primeiro, uma longa reflexão sobre a estrutura das coisas e, depois, uma teoria da medida aplicada às figuras da dança e às inflexões do canto. Assim, nas palavras do linguista, nada teria sido menos "natural" do que essa elaboração lenta, pelo esforço dos pensadores, de uma noção que nos parece tão necessariamente inerente às formas articuladas do movimento.

O linguista nos mostra que a noção de ritmo se transforma na e pela linguagem. Tal transformação é fruto de uma construção teórica, de uma reflexão teórica que se torna significativa e ganha, portanto, existência na e pela linguagem.

\section{Considerações finais}

Neste trabalho, discutimos a relação entre língua/linguagem e cultura em Benveniste, buscando, a partir daí, uma contribuição da obra do linguista para as ciências humanas.

Para tanto, tratamos inicialmente da relação entre língua/linguagem, homem, sociedade e cultura a fim de pensar como se constrói sua concepção de linguagem. Através da subversão da oposição entre natureza e cultura, Benveniste observa que a linguagem está na natureza do homem; assim, não é possível conceber a linguagem fora do homem nem tampouco o homem fora da linguagem. Além disso, o linguista também afirma que é um homem falando com outro homem que encontramos no mundo, o que nos mostra a relação constitutiva entre o "eu" e o "outro". A sociedade não se opõe, portanto, ao indivíduo, mas está com ele em uma relação de constituição mútua. Nessa mesma perspectiva, a cultura, em Benveniste, se torna significante na e pela linguagem. Com tal postura teórica, o linguista se distancia de estudiosos que 
pensam a cultura e a sociedade independentes da língua. Consequentemente, o autor se opõe a uma concepção de língua como espelho da sociedade ou simplesmente como um índice de suas mudanças.

A contribuição específica do linguista, segundo Benveniste, não se relaciona, então, com uma questão de designação - com um pressuposto extralinguístico -, mas com a questão da significação na e pela linguagem. Como mostra Meschonnic, Benveniste continua, por conseguinte, "por seu princípio dedutivo, a preocupação de Saussure, 'mostrar ao linguista o que ele faz' (Plg. II, 14)”5 (2008b, p. 388).

Partindo desse ponto de vista, trouxemos as análises do autor a respeito do termo superstição e da noção de ritmo para mostrar que a relação entre língua/linguagem e cultura é, antes de mais nada, uma questão de significação que decorre do uso, ou seja, dos diferentes empregos que a língua permite.

Benveniste explicita que os valores do termo superstição revelam diferentes visões de mundo que se constroem na e pela linguagem - o valor antigo, que diz respeito à cultura popular, e o valor moderno, que se refere à cultura romana tradicional. Por sua vez, discutindo a noção de ritmo, o linguista insiste no fato de que tal noção não é fruto de uma observação do mundo, mas, ao contrário, resulta de uma construção teórica e conceitual que só é possível através da linguagem.

Retomamos, desse modo, Meschonnic quando este afirma que Benveniste ocupa o lugar de um "inventor conceitual na teoria da linguagem" (ibid.), na medida em que para o linguista "a linguística é uma epistemologia" (2006d, p. 38), uma "teoria do conhecimento" (ibid.). Nesse sentido, as análises de Benveniste, especialmente aquelas encontradas nos dois volumes de $O$ vocabulário das instituições indo-europeias e na sexta parte dos Problemas,

\footnotetext{
5 Tradução nossa. No original: "par son principe déductif, le souci de Saussure, 'apprendre au linguiste ce qu'il fait"'.
}

se apresentam como uma "filologia da sociedade e do pensamento" que se diferencia de uma hermenêutica (Meschonnic, 2008b, p. 378).

Considerando o exposto, acreditamos que uma contribuição da obra de Benveniste para as ciências humanas passa sobretudo por sua concepção de linguagem. Partindo dessa concepção, não é mais possível conceber aprioristicamente o homem, a sociedade e a cultura; objetos que perpassam as diferentes disciplinas das ciências humanas. Tais objetos, desse ponto vista, se constroem sempre na e pela linguagem. Aí está, para nós, a mais significativa contribuição da teorização da linguagem proposta por Benveniste. Finalizamos, assim, trazendo as palavras de Dessons sobre o linguista, "suas proposições sobre o pensamento das relações da linguagem com a sociedade e a subjetividade se revelam de uma extraordinária lucidez", tais proposições, no entanto, "começam apenas a serem consideradas em toda a sua pertinência"6 no campo das ciências humanas (2006, p. 16).

\section{Referências}

BARROS, Diana Pessoa de. A comunicação humana. In: FIORIN, José Luiz (Org.). Introdução à Lingüística. São Paulo: Contexto, 2002. p. 25-54.

BENVENISTE, Émile. Da subjetividade na linguagem (1958). In: Problemas de lingüística geral, I. Trad. Maria da Glória Novak e Maria Luisa Neri. Campinas: Pontes, 2005a. p. 284-293.

A noção de "ritmo" na sua expressão lingüística (1951). In: Problemas de lingüística geral, I. Trad. Maria da Glória Novak e Maria Luisa Neri. Campinas: Pontes, 2005b. p. 361-370.

A linguagem e a experiência humana (1965). In: Problemas de lingüística geral, II. Trad. Marco Antônio Escobar. Campinas: Pontes, 2006a. p. 68-80.

6 Tradução nossa. No original: "ses propositions concernant la pensée des relations du langage, avec la société et la subjectivité se révèlent d'une remarquable lucidité" [..] "elles commencent seulement à être considérées dans toute leur pertinence". 
A forma e o sentido na linguagem (1966). In:

Problemas de lingüística geral, II. Trad. João Wanderlei Geraldi. Campinas: Pontes, 2006b. p. 220-242.

Estrutura da língua e estrutura da sociedade (1970). In: Problemas de lingüística geral, II. Trad. Rosa Attié Figueira. Campinas: Pontes, 2006c. p. 93-105.

Esta linguagem que faz a história (1968). In: Problemas de lingüística geral, II. Trad. Eduardo Guimarães. Campinas: Pontes, 2006d. p. 29-40.

Avant-propos. In: __. Le vocabulaire des institutions indo-européennes, 1. économie, parenté, société. Paris: Les Éditions de Minuit, 1969a. p. 7-13.

Religion et superstition. In:___. Le vocabulaire des institutions indo-européennes, 2. pouvoir, droit, religion. Paris: Les Éditions de Minuit, 1969b. p. 265-279.

DESSONS, Gérard. Émile Benveniste, l'invention du discours. Paris: Éditions IN PRESS, 2006.

MESCHONNIC, Henri. Crise de signe. In: Dans le bois de la langue. Paris: Éditions Laurence Teper, 2008a. p. 30-49.

Seul comme Benveniste. In: Dans le bois de la langue. Paris: Éditions Laurence Teper, 2008b. p. 359-389.

Recebido em 08/11/2015

Aceito em 26/12/2015 